\title{
Factors limiting the detection of sentinel lymph nodes in early-stage cervical cancer
}

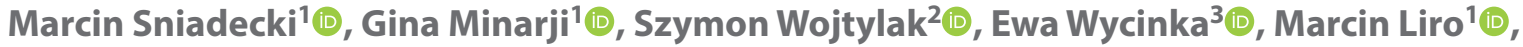 \\ Jerzy Iskrzycki ${ }^{4}$, , Dariusz Wydra ${ }^{1}$ (D) \\ ${ }^{1}$ Department of Gynecology, Gynecologic Oncology and Gynecologic Endocrinology, Medical University of Gdansk, Poland \\ ${ }^{2}$ Department of Pathology, Medical University of Gdansk, Poland \\ ${ }^{3}$ Department of Statistics, Faculty of Management, University of Gdansk, Sopot, Poland \\ ${ }^{4}$ Department of Endocrinology and Internal Medicine, Medical University of Gdansk, Poland
}

\begin{abstract}
Objectives: Sentinel lymph node detection (SLND) has not yet displaced lymphadenectomy, but it is a desired supplementary technique in cervical cancer surgery. The aim of our study was to identify the sources of SLND failure while performing the procedure by injecting blue dye (BD) into the cervix in cases of early-stage cervical cancer (ECC).

Material and methods: We analyzed 27 consecutive ECC patients (FIGO IA2-IB1) who underwent hysterectomy with SLND and systematic lymphadenectomy between October 2011 and June 2014. The main inclusion criterion was at least unilateral SLND by BD. Predictors of either unilateral or bilateral staining were identified using multinomial logit models and a decision tree.

Results: Overall, bilateral staining was achieved in nine patients (33\%). Among the factors analyzed, BMI $>23.5 \mathrm{~kg} / \mathrm{m}^{2}$ was the only factor negatively affecting the quality of SLND using BD $(p<0.02)$ in the univariable multinomial logit model. All patients with $\mathrm{BMI}<23.5 \mathrm{~kg} / \mathrm{m}^{2}$ and depth of invasion $\geq 15 \mathrm{~mm}$ had unilateral mapping.

Conclusions: Both obese and overweight patients are unlikely to achieve optimal SLN staining with BD alone. Although some possible reasons are discussed, we believe that further studies are needed to clarify the specific limitations of other dyes currently in use.
\end{abstract}

Key words: sentinel lymph node; cervical cancer; mapping techniques; gynaecological oncology; blue dye; limitations

Ginekologia Polska 2021; 92, 8: 556-562

\section{INTRODUCTION}

Cervical cancer has one of the highest mortality rates in the female population. Upon staging and assessing the progression of the cancer, it is possible to detect whether any sentinel lymph node (SLN) metastasis has occurred. To achieve this, a chemical tracer is widely used to map the lymph nodes. In addition to direct visualization by the physician during surgery, preoperative or intraoperative injection of tracers into the cervix is a method for assessing the cancer's spread [1-3].

Once excision of the SLN has been performed, it is important to achieve a histopathological determination of metastasis. After histopathological SLN assessment, a decision must be made regarding whether to perform lymphadenectomy or chemoradiation. Overtreatment is desirable to avoid in early-stage cervical cancer due to side effects $[4,5]$.
Bilateral staining (bilateral SLN detection) is effective as a credible inference of non-SLN status, and increases metastasis detection, including micrometastases [6]. In contrast, unilateral staining is perceived as unsatisfactory for the surgeon as well as the pathologist, requiring procedures to reduce the risk of false negative inferences on the status of lymph nodes (and therefore obligatory lymphadenectomy on the non-labeled side of the pelvis).

Many studies focus on the benefits and effectiveness of individual methods (sensitivity and specificity), and there are few publications on the causes of failure in detecting SLN. Reasons that have been identified for failures in mapping SLNs include (but are not limited to) the following: the type of tracer, whether a single tracer as opposed to a tracer combination is used, prior conization, tumor size, and patient age $[7,8]$.

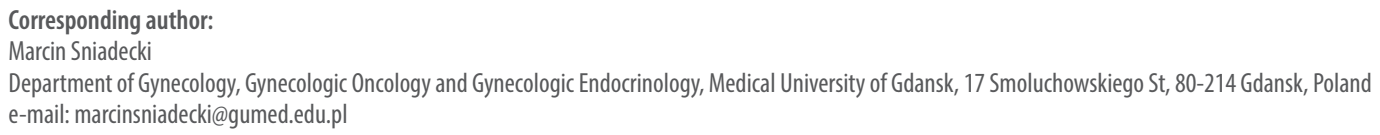




\section{Objectives}

The main purpose of this study was to identify the potential causes of false negative results of SLN identification methods using intracervical blue dye (BD) injections at early stages of cervical cancer on a cohort of patients from our previously published research [9]. The second aim of the current study was to review the limitations of other dyes currently used in SLND procedures in cases of early-stage cervical cancer.

\section{MATERIAL AND METHODS}

The participants in this retrospective single institution cohort study comprised of 27 patients with early-stage cervical cancer (IA2 and IB1) according to the International Federation of Gynecology and Obstetrics (FIGO 2009-2018) staging system, who were assessed between October 2011 and June 2014. The participants underwent either open or laparoscopic radical hysterectomy and lymphadenectomy with application of SLND as described in detail in our previously published study [9]. With the patient in the lithotomy position, methylene blue (Methyleen blauw, Sterop Pharmacobel, Belgium) was administered submucosally in four places in the amount of $1 \mathrm{~mL}(10 \mathrm{mg})$ per 1 needle puncture (size $22 \mathrm{G}$, Poly Medicure Ltd., India) at $3,6,9$, and 12 hours, each time about $0.5 \mathrm{~cm}$ from the edge of the cervical tumor. When the tumor occupied most of the cervix, the dye was applied to the free area of the cervix at least $0.5 \mathrm{~cm}$ from the tumor. Administration was performed in an operating room following anesthesia of the patient, approximately 15-20 minutes before surgical skin incision and approximately 15-25 minutes before opening the retroperitoneal space and the identification of $\operatorname{SLN}(\mathrm{s})$. Lymph nodes were considered sentinel when they were blue in color as described by the operator or pathologist, or a lymph pathway was identified that led to a specific lymph node or nodes.

Lymph nodes were removed, separating the labelled (sentinel) from the non-labelled (non-sentinel). Lymph node samples embedded in paraffin blocks were tested by serial sectioning of 4-micrometre slides every $150 \mu \mathrm{m}$ and evaluated by ultrastaging using anti-cytokeratin (CK) AE1/AE3 monoclonal antibodies. Sections were placed on silanized slides, two sections from a given section: one for haematoxylin and eosin (HE) staining, and the other for antibody reaction CK $A E 1 / A E 3$. The staining directions (unilateral, bilateral) of the SLNs were correlated to clinical data [age, body mass index (BMI), anamnesis], postoperative tumor size, depth of invasion, the subjective quality of the BD application, the experience of the physician injecting the $\mathrm{BD}$ (novice $\leq 1$ year of work in gynecological oncology unit, moderate $1 \geq 5$ years, and experienced $>5$ years), and identification of large $(>2 \mathrm{~cm}$ ) nodes postoperatively (or intraoperatively) in the pelvis. Two methods were used for qualitative predictors: loglikelihood chi-square test (chi-square $\mathrm{ML}$ ) and univariate multinomial logit models. The second of these was also used for quantitative predictors. The normality of distributions of the quantitative predictors was verified with the use of three different tests: Kolmogorov-Smirnov, Lilliefors and Shapiro-Wilk. Results were indicated in the boxplots which represent the distribution of the predictors according to the directions of the staining. Furthermore, a decision tree was used to find the decision algorithm and the importance of the predictors.

\section{RESULTS}

In nine of the 27 (33\%) patients, bilateral pelvic SLN staining was achieved. As seen in Table 1, participant data on various parameters relevant to the study were collected and analyzed based. There were no significant differences between the distributions of age, depth of infiltration and postoperative size of the tumour or pelvic nodes in terms of staining direction. There was also no significant combination of predictors shown by the multivariable multinomial logit model (Tab. 2). Furthermore, using the univariate ANOVA test (Tab. 3), BMI was the only factor shown to be significant for staining direction, with a predictive value above $23.5 \mathrm{~kg} / \mathrm{m}^{2}$. The median value of BMI for patients with bilateral staining was lower than in the cases with unilateral staining and the same applied to the dispersion of BMI in that group. In the post-hoc analysis, the BMI differed between the left and bilateral successful staining groups, with higher values occurring in the left-stained group (Tab. 4). Consequently, we may divide patients into two groups: patients with BMI above $23.5 \mathrm{~kg} / \mathrm{m}^{2}$ and patients with BMI below this value. Patients with BMI below $23.5 \mathrm{~kg} / \mathrm{m}^{2}$ achieved bilateral staining, whereas patients with BMl above $23.5 \mathrm{~kg} / \mathrm{m}^{2}$ achieved unilateral staining. Furthermore, sub-dividing the group with BMI below $23.5 \mathrm{~kg} / \mathrm{m}^{2}$ into two groups: 1) those with

Table 1. Patients characteristics in a cohort of 27 patients

\begin{tabular}{|l|l|}
\hline Characteristic & Value \\
\hline Age [years] & $23-65$ (median 54) \\
\hline BMI $\left[\mathrm{kg} / \mathrm{m}^{2}\right]$ & $19-37$ (median 25) \\
\hline PID in anamnesis (number of patients, \%) & $1(3.7)$ \\
\hline $\begin{array}{l}\text { Previous use of contraceptives (number } \\
\text { of patients, \%) }\end{array}$ & $3^{*}(11)$ \\
\hline $\begin{array}{l}\text { Previous cervical surgery (number of } \\
\text { patients, \%) }\end{array}$ & $10(37)$ \\
\hline $\begin{array}{l}\text { Time between cervical surgery and } \\
\text { hysterectomy [days] }\end{array}$ & $\begin{array}{l}13-2550 \\
(\text { mean 320.67) }\end{array}$ \\
\hline $\begin{array}{l}\text { Previous pelvic surgery (number of } \\
\text { patients, \%) }\end{array}$ & $6(22)$ \\
\hline
\end{tabular}

$\mathrm{BMI}$ - body mass index; PID — pelvic inflammatory disease; *in one case intrauterine device was used, in two cases - oral contraceptives were used 


\begin{tabular}{|c|c|c|c|c|}
\hline \multirow{3}{*}{$\begin{array}{l}\text { Predictors } \\
\text { Previous cervical surgery }\end{array}$} & \multirow{2}{*}{\multicolumn{2}{|c|}{$\begin{array}{l}\text { loglikelihood chi-square } \\
\text { test }\end{array}$}} & \multirow{3}{*}{$\begin{array}{l}\text { p value } \\
p=0.10103\end{array}$} & \multirow{3}{*}{\begin{tabular}{|l|} 
Univariable multinomial logit model \\
p value \\
0.101 \\
\end{tabular}} \\
\hline & & & & \\
\hline & 4.584641 & $d f=2$ & & \\
\hline Previous pelvic surgery & 1.357020 & $d f=2$ & $p=0.50737$ & 0.507 \\
\hline Histological type & 7.379678 & $\mathrm{df}=4$ & $p=0.11713$ & 0.025 \\
\hline The quality of the marker's application & 4.603175 & $\mathrm{df}=4$ & $p=0.33049$ & 0.100 \\
\hline Experience & 1.826553 & $d f=2$ & $p=0.40121$ & 0.401 \\
\hline Large lymph nodes [ $>2 \mathrm{~cm}$ in greatest dimension] & 5.265428 & $\mathrm{df}=2$ & $p=0.76853$ & 0.769 \\
\hline Age [years] & & & & 0.126 \\
\hline BMI $\left[\mathrm{kg} / \mathrm{m}^{2}\right]$ & & & & 0.018 \\
\hline Size of postoperative tumor $[\mathrm{cm}]$ & & & & 0.108 \\
\hline Depth of infiltration [mm] & & & & 0.396 \\
\hline
\end{tabular}

$\mathrm{BMI}$ - body mass index

Table 3. Univariate ANOVA tests for quantitative predictors

\begin{tabular}{|l|l|l|l|l|}
\hline \multirow{2}{*}{ Variable } & Levene Test (for variance) & \multicolumn{2}{l|}{ ANOVA } & p value \\
\cline { 2 - 5 } & F & p value & F & 0.144509 \\
\hline Age & 0.246028 & 0.783849 & 2.099059 & 0.038580 \\
\hline Body mass index & 0.663798 & 0.524092 & 3.739278 & 0.430938 \\
\hline Depth of infiltration & 1.182010 & 0.323888 & 0.872018 & 0.6344 \\
\hline Postoperative tumor size $[\mathrm{cm}]^{*}$ & & & 0.9100886 & \\
\hline
\end{tabular}

*Kruskal Wallis test

\begin{tabular}{|l|l|l|l|}
\hline \multicolumn{4}{|l|}{ Table 4. Post-hoc tests for increased weight } \\
\hline \multirow{2}{*}{$\begin{array}{l}\text { Direction of } \\
\text { staining }\end{array}$} & \multicolumn{3}{|l|}{ RIR Tukey's test; variable: WEIGHT (BMI) } \\
\cline { 2 - 4 } & $\begin{array}{l}\{1\} \\
\mathbf{M}=\mathbf{2 7 . 4 4 4}\end{array}$ & $\begin{array}{l}\{2\} \\
\mathbf{M}=\mathbf{2 2 . 4 4 4}\end{array}$ & $\begin{array}{l}\{3\} \\
\mathbf{M}=\mathbf{2 6 . 7 2 1}\end{array}$ \\
\hline left $\{1\}$ & & 0.046760 & 0.929121 \\
\hline bilateral $\{2\}$ & 0.046760 & & 0.098288 \\
\hline right $\{3\}$ & 0.929121 & 0.098288 & \\
\hline
\end{tabular}

$\mathrm{BMI}$ - body mass index

cancer stromal invasion below $15 \mathrm{~mm}$, and 2) those with cancer stromal invasion equal to or greater than $15 \mathrm{~mm}$, thus showing that in the first sub-group the bilateral staining was dominating, whereas in the second sub-group the staining was only unilateral. Returning to the group containing patients with BMl above $23.5 \mathrm{~kg} / \mathrm{m}^{2}$, those patients who were younger than 62.5 years typically showed left-sided staining compared to the group with BMI above $23.5 \mathrm{~kg} / \mathrm{m}^{2}$ which showed a trend towards right-sided unilaterality (Fig. 1).

Across the whole study group, those with the histopathological subtype of squamous cell carcinoma and unilateral staining outnumbered those with squamous cell carcinoma and bilateral staining, while in the adenocarcinoma subtype there was a tendency for unilateral SLN mapping (Fig. 2). In the case of previous cervical surgery there were much fewer patients with right-sided mapping (only 1 in our sample group) than those who had not undergone surgery. There were no differences in the numbers of left and bilateral staining (Fig. 3). Highly experienced physicians identified bilateral nodes to a greater extent than their less-experienced colleagues (Fig. 4). Figure 5 shows lipomatous atrophy found in the pelvic lymph node of the patient who had only one side of the pelvis mapped with success.

\section{DISCUSSION}

While in our previous study [9] there was no room for elaborating the topic in this regard, the aim of our present study was to provide possible explanations for the fact that bilateral staining occurred in less than half of the study subjects. Predictors of either unilateral or bilateral staining were identified using multinomial logit models and a decision tree. The main result of the study shows that both overweight and obese patients are unlikely to achieve optimal SLN staining with BD alone. One of the reasons for that is the lateralization of the SLN staining that occurs with dye. It is increasingly important to identify the precise extent of lymph node metastasis in order to avoid any over-resection of healthy tissue, in consideration of patients' quality of life after treatment. The dye markers, among which blue dyes are mainly used, included: aniline derivatives (patent blue 


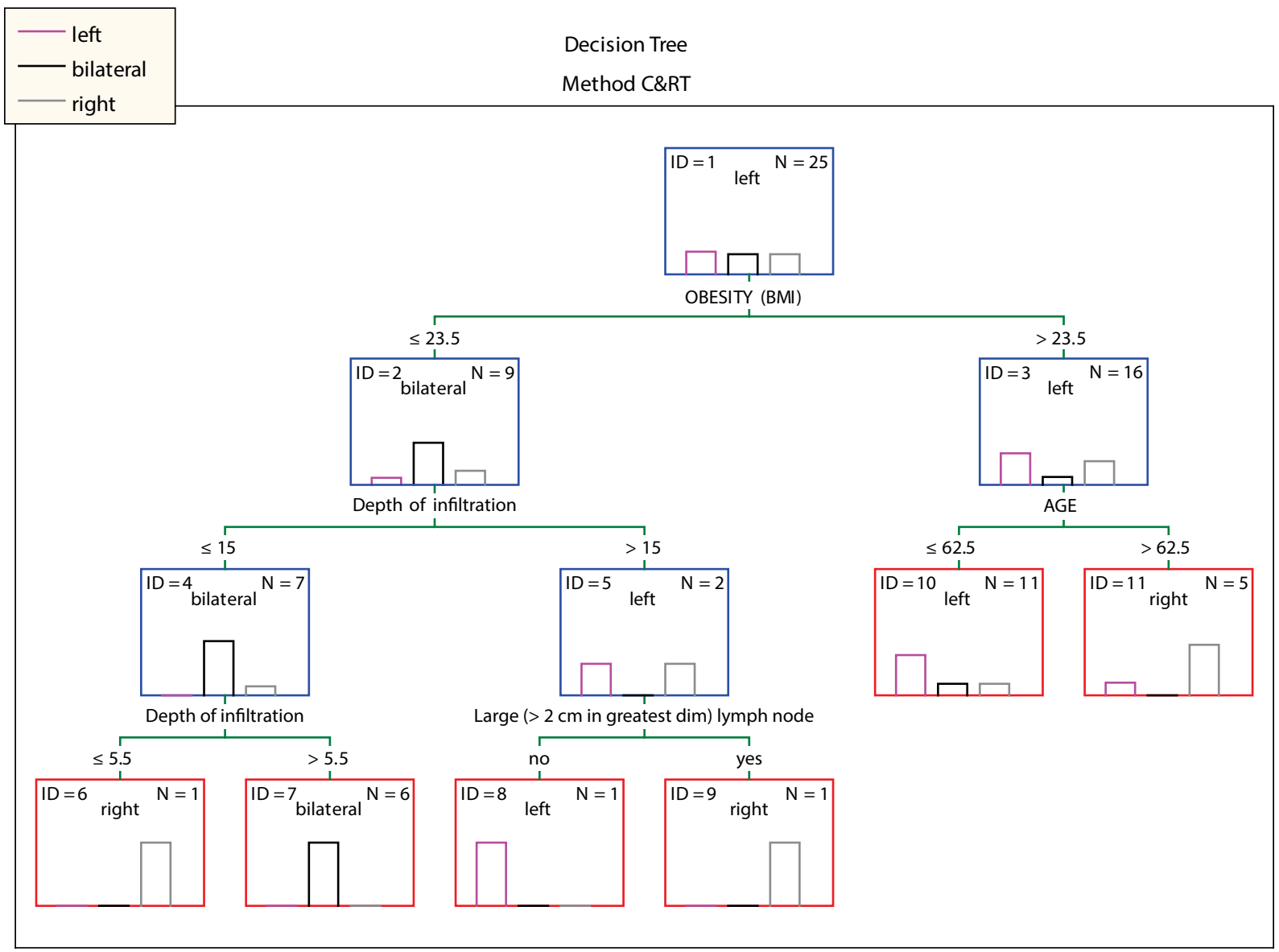

Figure 1. Decision tree comprising obestity, age and depth of infiltration; BMI — body mass index; ID — node numbers (there are 9 different types of lymph nodes in total in the statistical analysis); $\mathrm{N}$ - is the number of units (patients in the node)

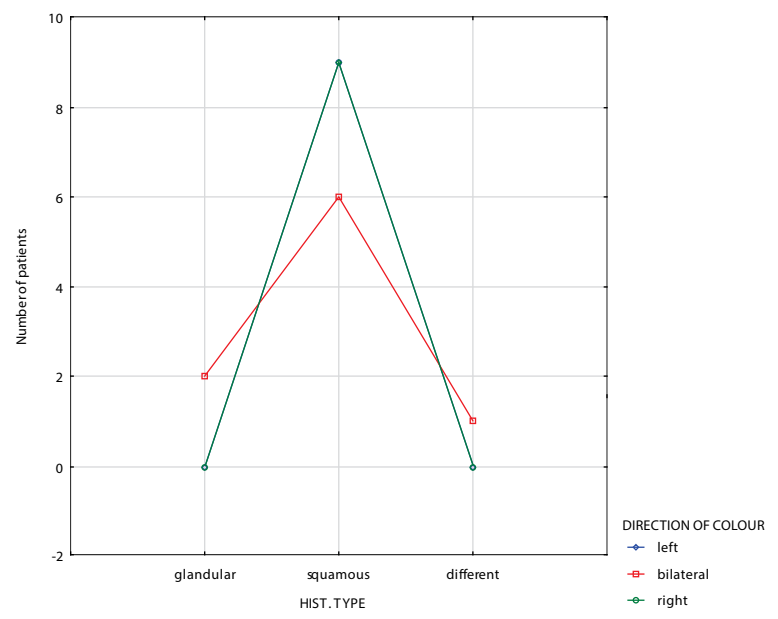

Figure 2. The interaction plot showing distributions of number of patients simultaneously due to histological type and direction of color

V, Patentblau — V; alfazurin, Alphazurin, lymphazurin, Lymphazurin) and methylene blue. The choice of methylene blue was dictated by the practice used in the clinic. Methylene blue is a widely available and relatively inexpensive dye, that does not require additional facilities, and in our study, it was

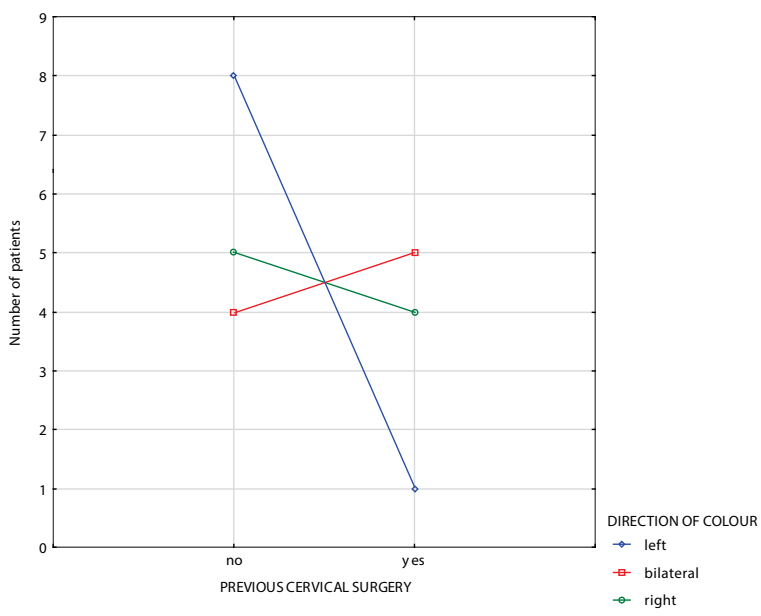

Figure 3. The interaction plot showing distributions of number of patients simultaneously due to previous cervical surgery and direction of color

used as a supplementary diagnostic procedure for planned lymphadenectomy. Our study was designed to evaluate the efficacy of methylene blue dye that was being administered in a single institution in a cohort of patients with early-stage cervical cancer. Only two factors proved to be 


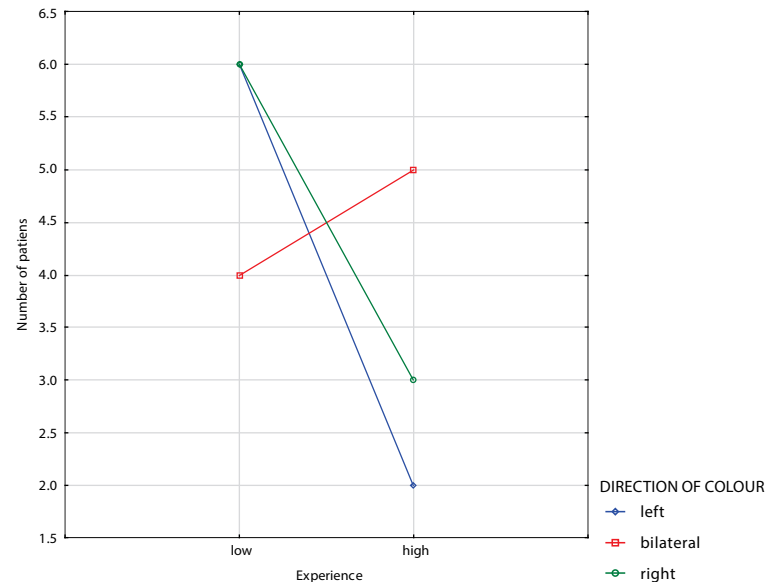

Figure 4. The interaction plot showing distributions of number of patients simultaneously due to experience of physician and direction of color

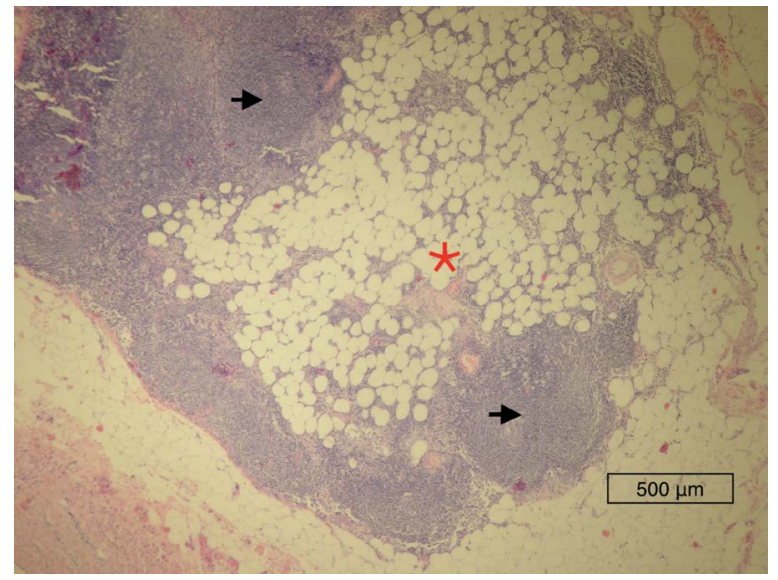

Figure 5. Lipomatous atrophy in the pelvic lymph node; A pelvic lymph node in a patient who has overweight $\left(26 \mathrm{~kg} / \mathrm{m}^{2}\right)$ and a sentinel lymph node mapping failure. The lymph node begins to turn off functionally from the lymphatic plexus and lymph ceases to flow through part of the node. Lipomatous atrophy is formed in place of the structure of the lymph node (asterisk). However, preexistent lymph node structure (arrows) does not exclude lymph node metastasis

significant causes of lateralizing hemipelvis staining: a BMI higher than $23.5 \mathrm{~kg} / \mathrm{m}^{2}$ and histopathological subtypes of cervical carcinoma. Other analyzed factors such as gynecological anamnesis, age, experience of physician injecting the $\mathrm{BD}$, size of tumor, size of lymph nodes, and histological type were insignificant in relation to the quality of detection of reactive lymph nodes.

The techniques for labelling SLN involve administering the tracers in a manner that allows them to reach from the vicinity of the primary tumor or from the primary tumor itself to each lymph node connected to it by a lymph vessel. Among those currently used, there are dye-based, isotopic either with or without lymphoscintigraphy, and dye-isotopic methods; and in the field of clinical research there are isotope-free methods, either using the paramagnetic properties of tissue or specifically designed markers showing the reaction to infrared light (i.e., indocyanine green, ICG). Physicians prefer dye tracers for its simplicity, as it is injected pre-operatively directly into the four quadrants or two sides of the uterine cervix under general anesthesia, and there is no need to consult a nuclear medicine department as is the case when technetium-99m-labeled human serum albumin is injected. These aspects offer comfort and confidence. Other reasons for preferring dye tracers over other types are their lower cost, that there is no need for special visualization systems, and no need for a central pharmacy to prepare the dye. However, the rate of false negative results associated with the use of BD requires consideration [10-13].

Overweight/obesity is a worldwide problem that continues to grow, especially in developed countries. Abnormal BMI not only increases the risk of many neoplastic diseases, but also affects the outcomes of many medical procedures.

A substantial proportion of patients undergoing surgery for cervical cancer are overweight or obese. This is an issue when one considers the recent European Society of Gynecological Oncology recommendations that say open surgery in cervical cancer is the gold standard for the treatment of patients with this type of cancer [14]. Among possible reasons that overweight and obesity affect the results of sentinel node labeling, are the dispersion of the chemical tracer across a greater body surface area (i.e., too-low doses are administered) and metabolism. Recent studies have shown that the use of ICG can bypass obesity-related problems with SLN staining $[15,16]$. Although obesity itself is defined as a BMI value of above $30 \mathrm{~kg} / \mathrm{m}^{2}$, our study showed an unfavorable trend beginning as low as $23.5 \mathrm{~kg} / \mathrm{m}^{2}$, meaning that the risk of false negative outcomes increased at values well below the officially recognised lower threshold of overweight status. As studies have shown that this issue can partly be bypassed with the application of ICG, the use of this dye tracer is advisable. However, it must be noted that even with the application of ICG, completely bypassing the effects of overweight/obesity is not possible since this tracer has shown increased false negative results at elevated BMIs (although the BMIs producing negative results for ICG are higher than those for methylene and isosulfan blue dyes). The conclusion to be drawn is that although these tracers provide false-negative results at higher BMIs, the false-negative rates are considerably lower when using ICG than when applying methylene or isosulfan blue tracers $[17,18]$. The reasons for poor bilateral staining results with $\mathrm{BD}$ may be because in cases where there are patients with a higher BMI and relatively low expertise of those conducting the procedure, and the difficulty of gaining a clear view of the surgical field (i.e., more fat tissue, more rapid tracer penetration into this tissue), it becomes easier to make an error when applying the tracer into the cervix 
Table 5. Methods for sentinel lymph nodes mapping in gynecological oncology

\begin{tabular}{|c|c|c|c|c|}
\hline Mapping method & Benefits & Defects & Limitations in cervical cancer & References \\
\hline $\begin{array}{l}\text { Dye } \\
\text { (isosulfan blue, } \\
\text { methylene blue, } \\
\text { patent blue violet) }\end{array}$ & $\begin{array}{l}\text { It does not require } \\
\text { advanced facilities of the } \\
\text { nuclear medicine ward, } \\
\text { avoiding radiation }\end{array}$ & $\begin{array}{l}\text { Demanding technique (role } \\
\text { of experience), possibility of } \\
\text { allergic reactions, tattoos, } \\
\text { quantitative measurement } \\
\text { impossible }\end{array}$ & $\begin{array}{l}\text { Dependence on favorable operational } \\
\text { field exposure, avoiding dilution of } \\
\text { the dye (rapid absorbing to lymphatic } \\
\text { pathway), blue dye dosage and site } \\
\text { of injection, the time between dye } \\
\text { injection and the operative procedure } \\
\text { (risk of moving of BD on to the non- } \\
\text { sentinel lymph nodes) }\end{array}$ & $\begin{array}{l}\text { Jarruwale et al. } \\
2012\end{array}$ \\
\hline $\begin{array}{l}\text { With the use of } \\
\text { infrared light } \\
\text { (fluorescent dye) }\end{array}$ & $\begin{array}{l}\text { It does not require } \\
\text { advanced facilities of the } \\
\text { nuclear medicine ward, } \\
\text { avoiding radiation }\end{array}$ & $\begin{array}{l}\text { Requires a special } \\
\text { intraoperative detection } \\
\text { system; the possibility of } \\
\text { an allergic reaction, tattoos }\end{array}$ & $\begin{array}{l}\text { Spilling from the lymphatic system } \\
\text { during lymph node dissection due } \\
\text { to small size of particles, presence of } \\
\text { metastatic lymph nodes }\end{array}$ & $\begin{array}{l}\text { Cheng-Yen Lai et al. } \\
\text { 2018, Bedynska et } \\
\text { al. } 2019\end{array}$ \\
\hline $\begin{array}{l}\text { Radioisotope } \\
\text { ( }{ }^{99 m} \text { Tc-labeled } \\
\text { nanocolloids) }\end{array}$ & $\begin{array}{l}\text { Higher sensitivity } \\
\text { and specificity in } \\
\text { the detection of SLN } \\
\text { compared to the } \\
\text { dye technique itself, } \\
\text { quantification of uptake }\end{array}$ & $\begin{array}{l}\text { Expensive, requiring } \\
\text { (less than in the case of } \\
\text { lymphoscintigraphy) } \\
\text { facilities of the nuclear } \\
\text { medicine facility (qualified, } \\
\text { interdisciplinary staff), } \\
\text { contraindicated in pregnant } \\
\text { women and lactation }\end{array}$ & $\begin{array}{l}\text { Primary tumor site, scanned timing } \\
\text { before } S L N \text { can uptake radioactive } \\
\text { matters, different infusion areas, size of } \\
\text { investigating materials }\end{array}$ & $\begin{array}{l}\text { Jarruwale et al. } \\
2012\end{array}$ \\
\hline $\begin{array}{l}\text { Preoperative } \\
\text { lymphoscintigraphy }\end{array}$ & $\begin{array}{l}\text { High sensitivity and } \\
\text { specificity in SLN } \\
\text { detection, quantitative } \\
\text { uptake assessment, } \\
\text { useful in so-called } \\
\text { "Learning curve", testing } \\
\text { new combinations, e.g. } \\
\text { Tilmanocept* }\end{array}$ & $\begin{array}{l}\text { Expensive, requiring nuclear } \\
\text { medicine facilities (qualified, } \\
\text { interdisciplinary staff), having } \\
\text { a gamma camera)* }\end{array}$ & $\begin{array}{l}\text { Primary tumor site, scanned timing } \\
\text { before SLN can uptake radioactive } \\
\text { matters, different infusion areas, size of } \\
\text { investigating materials }\end{array}$ & $\begin{array}{l}\text { Jarruwale et al. } \\
2012 \text {, Surasi et al. } \\
2015\end{array}$ \\
\hline Paramagnetic & $\begin{array}{l}\text { Low cost and outlay } \\
\text { of hardware facilities } \\
\text { compared to the results } \\
\text { obtained, quantification } \\
\text { of uptake }\end{array}$ & $\begin{array}{l}\text { Requiring nuclear medicine } \\
\text { facilities (qualified, } \\
\text { interdisciplinary staff, having } \\
\text { the appropriate detector) }\end{array}$ & Not yet available for cervical cancer & \\
\hline
\end{tabular}

*for tilmanocept, no agreed good practice for cervical cancer; BD — blue dye; SLN —-sentinel lymph node

(i.e., incomplete application, technical difficulties). In Table 5 , we have provided a comparison of different lymph node labelling method [7, 17-20]. Although lipomatous atrophy in the lymph nodes has not been linked with obesity in the literature, one may consider such an association. In several patients with hemi-pelvis mapping, we observed this condition of the lymph nodes ( $2-5$ per patient on the contralateral side), while in the group with bilateral staining we found such lymph nodes less frequently ( $0-2$ per patient). The number of patients in this study is limited and the condition of lipomatous atrophy is too common to draw specific conclusions on this topic.

\section{CONCLUSIONS}

This study has some limitations. One limitation was related to the low number of samples. Having studied only 27 patients, the results may have produced inaccuracies which may have been avoided if the number of samples was greater. Another limitation was related to the relatively high number of physicians involved in injecting the dye. The physicians possessed different levels of experience and expertise. The third limitation relates to the fact that blue dye is no longer the preferred method for detecting SLNs as other dye tracers have been shown to be superior. However, that was not the case several years ago when the study was commenced. The fourth and last concern is the decision tree used. However, it is of importance to remember that the decision tree is not a statistical test but simply a system for the division of units based on a chosen classification measure. It can occur that it shows the rule which exists in the sample but not in the population. Thus, in our opinion it is helpful to use decision trees to formulate rather than prove hypotheses. Due to the small sample size, we were unable to find excessive rules and deviations since a decision tree easily creates individual groups. Nevertheless, we believe that further analyses that take into consideration obese and non-obese patients would have scientific value.

\section{Funding details}

The study was conducted within the framework of the research project of the Department of Gynaecology, Gynaecologic Oncology and Gynaecologic Endocrinology, Medical 
University of Gdansk: "Application of sentinel lymph node and assessment of the occurrence of micrometastases in gynaecologic oncology" (grant ref. no. ST 02/00-74/07). The study received the approval of the Bioethics Commission of the Medical University of Gdansk (no. NKBBN/321/2013).

\section{Conflict of interest}

No potential conflicts of interest were reported by the authors.

\section{REFERENCES}

1. López-De la Manzanara Cano C, Cordero García JM, Martín-Francisco C, et al. Sentinel lymph node detection using $99 \mathrm{mTC}$ combined with methylene blue cervical injection for endometrial cancer surgical management: a prospective study. Int J Gynecol Cancer. 2014; 24(6): 1048-1053, doi: 10.1097/IGC.0000000000000158, indexed in Pubmed: 24927249.

2. Cibula D, Oonk MHM, Abu-Rustum NR. Sentinel lymph node biopsy in the management of gynecologic cancer. Curr Opin Obstet Gynecol. 2015; 27(1): 66-72, doi: 10.1097/GCO.0000000000000133, indexed in Pubmed: 25502426.

3. Salvo G, Ramirez PT, Levenback CF, et al. Sensitivity and negative predictive value for sentinel lymph node biopsy in women with early-stage cervical cancer. Gynecol Oncol. 2017; 145(1): 96-101, doi: 10.1016/j. ygyno.2017.02.005, indexed in Pubmed: 28188015.

4. Seong SJu, Park H, Yang KM, et al. Detection of sentinel lymph nodes in patients with early stage cervical cancer. J Korean Med Sci. 2007; 22(1): 105-109, doi: 10.3346/jkms.2007.22.1.105, indexed in Pubmed: 17297260.

5. Ferrandina G, Distefano M, Mascilini F, et al. Could lymphadenectomy be avoided in locally advanced cervical cancer patients administered preoperative chemoradiation? A large-scale retrospective study. Eur J Surg Oncol. 2017; 43(12): 2270-2276, doi: 10.1016/j.ejso.2017.09.013, indexed in Pubmed: 28988767.

6. Cibula D, Abu-Rustum NR, Dusek $L$, et al. Bilateral ultrastaging of sentinel lymph node in cervical cancer: Lowering the false-negative rate and improving the detection of micrometastasis. Gynecol Oncol. 2012; 127(3): 462-466, doi: 10.1016/j.ygyno.2012.08.035, indexed in Pubmed: 22943880.

7. Jarruwale $P$, Huang KG, Benavides $D$, et al. Factors related to sentinel node identification in cervical cancer. Gynecology and Minimally Invasive Therapy. 2012; 1(1): 19-22, doi: 10.1016/j.gmit.2012.08.001.

8. Kadkhodayan S, Hasanzadeh M, Treglia G, et al. Sentinel node biopsy for lymph nodal staging of uterine cervix cancer: a systematic review and meta-analysis of the pertinent literature. Eur J Surg Oncol. 2015; 41(1): 1-20, doi: 10.1016/j.ejso.2014.09.010, indexed in Pubmed: 25454828.
9. Sniadecki M, Wydra DG, Wojtylak S, et al. The impact of low volume lymph node metastases and stage migration after pathologic ultrastaging of non-sentinel lymph nodes in early-stage cervical cancer: a study of 54 patients with 4.2 years of follow up. Ginekol Pol. 2019; 90(1): 20-30, doi: 10.5603/GP.2019.0004, indexed in Pubmed: 30756367.

10. Tanaka T, Terai Y, Ashihara K, et al. The detection of sentinel lymph nodes in laparoscopic surgery for uterine cervical cancer using $99 \mathrm{~m}$-technetium-tin colloid, indocyanine green, and blue dye. J Gynecol Oncol. 2017; 28(2): e13, doi: 10.3802/jgo.2017.28.e13, indexed in Pubmed: 27894166.

11. Gasparri M, Mueller M, Papadia A. Instead of feeling blue, go green! The Lancet Oncology. 2018; 19(10): 1273-1274, doi: 10.1016/s1470-2045(18)30514-x.

12. Buda A, Papadia A, Zapardiel I, et al. From Conventional Radiotracer Tc-99(m) with Blue Dye to Indocyanine Green Fluorescence: A Comparison of Methods Towards Optimization of Sentinel Lymph Node Mapping in Early Stage Cervical Cancer for a Laparoscopic Approach. Ann Surg Oncol. 2016; 23(9): 2959-2965, doi: 10.1245/s10434-016-5227-y, indexed in Pubmed: 27126631.

13. Buda A, Di Martino G, Vecchione F, et al. Optimizing Strategies for Sentinel Lymph Node Mapping in Early-Stage Cervical and Endometrial Cancer: Comparison of Real-Time Fluorescence With Indocyanine Green and Methylene Blue. Int J Gynecol Cancer. 2015; 25(8): 1513-1518, doi: 10.1097/IGC.0000000000000526, indexed in Pubmed: 26397069.

14. Querleu D. Laparoscopic radical hysterectomy: an ESGO statement. https://www.esgo.org/explore/council/laparoscopic-radical-hysterectomy-an-esgo-statement/ (26.06.2020).

15. Tanner EJ, Sinno AK, Stone RL, et al. Factors associated with successful bilateral sentinel lymph node mapping in endometrial cancer. Gynecol Oncol. 2015; 138(3):542-547, doi: 10.1016/j.ygyno.2015.06.024, indexed in Pubmed: 26095896.

16. Eriksson AG, Montovano M, Beavis A, et al. Impact of Obesity on Sentinel Lymph Node Mapping in Patients with Newly Diagnosed Uterine Cancer Undergoing Robotic Surgery. Ann Surg Oncol. 2016; 23(8): 2522-2528, doi: 10.1245/s10434-016-5134-2, indexed in Pubmed: 26905542.

17. Cheng-Yen Lai J, Yang MS, Lu KW, et al. The role of sentinel lymph node biopsy in early-stage cervical cancer: A systematic review. Taiwan J Obstet Gynecol. 2018; 57(5): 627-635, doi: 10.1016/j.tjog.2018.08.003, indexed in Pubmed: 30342641

18. Bedyńska M, Szewczyk G, Klepacka T, et al. Sentinel lymph node mapping using indocyanine green in patients with uterine and cervical neoplasms: restrictions of the method. Arch Gynecol Obstet. 2019; 299(5): 1373-1384, doi: 10.1007/s00404-019-05063-6, indexed in Pubmed: 30762108 .

19. Di Martino G, Crivellaro C, De Ponti E, et al. Indocyanine green versus radiotracer with or without blue dye for sentinel lymph node mapping in stage $>\mid B 1$ cervical cancer (>2 cm). J Minim Invasive Gynecol. 2017; 24(6): 954-959, doi: 10.1007/s00404-019-05063-6.

20. Surasi DS, O'Malley J, Bhambhvani P, et al. $99 \mathrm{mTC}$-Tilmanocept: A novel molecular agent for lymphatic mapping and sentinel lymph node localization. J Nucl Med Technol. 2015; 43(2): 87-91, doi: 10.1007/s00404-019-05063-6. 